\title{
Radioactivity and thyroid cancer ${ }^{*}$
}

\author{
Christopher Reiners
}

Clinic and Polyclinic of Nuclear Medicine University of Würzburg

\begin{abstract}
There is no evidence that natural radiation (cosmic radiation or from natural radioiosotopes) increases the risk for thyroid diseases. Moreover, while it has been proven that exposure to external medical radiation or to external and internal radiation by atomic bomb explosions leads to an increased risk for thyroid cancer, the medical use of radioiodine, namely diagnostic and therapeutic application of ${ }^{131} I$, is safe and does not induce thyroid cancer. Exposure of children aged less than 4 years to fallout from the Chernobyl reactor accident has led to a substantial increase of childhood cancer incidence in the countries affected (Belarus, Ukraine and Western parts of Russia). Up to now, the total number of cases in children and adolescents adds up to approximately 5,000; in the next 50 years, approximately 15,000 additional thyroid cancer cases in this age group are expected. With respect to the Chernobyl effects on adults, there is no proven radiation related increase of the thyroid cancer incidence. As can be proven by a therapy project in 247 children with advanced thyroid cancer from Belarus, the prognosis for this tumor, even when metastasized, is good, this being in accordance with literature data indicating mortality rates between 1 and $2 \%$.
\end{abstract}

Key words: Children, Radiation, Thyroid Cancer

\section{EXPERIENCES WITH EXTERNAL RADIATION EXPOSURE}

Knowledge accumulated for more than 50 years has shown that exposure to external radiation is associated with harmful effects to the thyroid, such as hypothyroidism, thyroid autoimmunity, thyroid nodules and thyroid cancer. ${ }^{1}$ There are several longitudinal cohort studies which provide clear data on the long-term risks for thyroid cancer and other

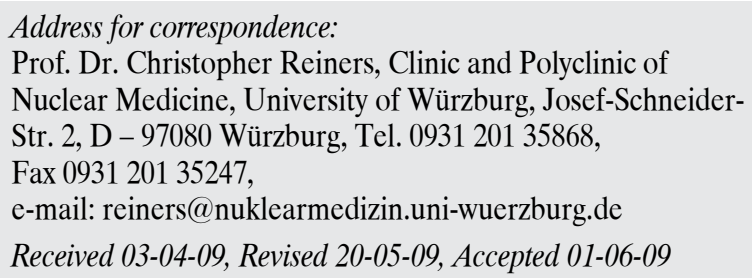

neoplasms after thyroid exposure to radiation. ${ }^{2}$ The most vulnerable subjects are children (Table 1), as has been shown in a comprehensive summary by $\mathrm{E}$. Ron et al. ${ }^{3}$

Other data come from the long-term follow-up of survivors from atomic bomb detonations in Japan., ${ }^{4,5}$ With respect to age-dependence, Thompson et $\mathrm{al}^{6}$ showed that there is a very significant increase in thyroid cancer risk in the age-group 0-9 years, a less, though highly significant risk, in subjects younger than 20 years, and no appreciably increased thyroid cancer risk in individuals past the age of 20 (Table 2).

\footnotetext{
* Presented in part at the International Meeting on "Thyroid Cancer and Environment", 8-10 June, 2007, Santorini, Greece
} 
Table 1. Thyroid cancer after exposure of children to irradiation for various indications: Cohort and Screening Studies in Children ${ }^{3}$

\begin{tabular}{lcccc}
\hline Study/Indication & Observed cases & Expected cases & Mean radiation dose (Sv) & Average excess RR at 1Sv \\
\hline Life Span Study (0-19y) & 59 & 22.2 & 0.26 & $* 6.3$ (95\% CI: 5.1-10.1) \\
Israeli Tinea Capitis & 43 & 10.7 & 0.1 & $* 34$ (95\% CI: 23-47) \\
Rochester Thymus & 37 & 2.7 & 1.4 & $* 9.5$ (95\% CI: $6.9-12.7)$ \\
Lymphoid Hyperplasia & 13 & 5.4 & 0.24 & $* 5.9(95 \%$ CI: $1.8-11.8)$ \\
Michael Reese Tonsils & 309 & 110.4 & 0.6 & $* 3.0(95 \%$ CI: $2.6-3.5)$ \\
Total & 436 & -- & -- & $* 4.4(95 \%$ CI: $1.9-10.1)$ \\
\hline
\end{tabular}

Sv: Organ dose, RR: Relative Risk, *Significant

Table 2. Thyroid cancer after radiation according to gender and age at exposure: The Life Span Study from Japanese A-Bomb Survivors ${ }^{6}$

\begin{tabular}{lcccc}
\hline Study/Indication & Observed cases & Expected cases & Mean radiation dose (Sv) & Average excess RR at 1Sv \\
\hline Total & 132 & 94.3 & 0.26 & $1.5(95 \%$ CI:0.5-2.1) \\
Gender & 22 & 14.9 & 0.27 & 1.80 \\
$\quad$ males & 110 & 79.4 & 0.26 & 1.49 \\
$\quad$ females & & & & $* 10.25$ \\
Age at exposure & 24 & 7.6 & 0.21 & $* 4.50$ \\
$0-9$ & 35 & 14.6 & 0.31 & 0.10 \\
$10-19$ & 18 & 17.5 & 0.28 & \\
$20-29$ & & & \\
\hline
\end{tabular}

Sv: Organ dose, RR: Relative Risk, *Significant

Because of this age-relation, small children in particular should be very efficiently protected against the possible hazards of ionizing radiation.

\section{THYROID CANCER AFTER MEDICAL EXPOSURE TO RADIOIODINE}

Comprehensive data from a Swedish longitudinal cohort study of 36,792 subjects exposed to diagnostic activities of radioiodine $\left({ }^{131} \mathrm{I}\right)$ indicate a small but significant increase in thyroid cancer. However, if the analysis is performed separately in those who were referred for diagnosis of suspected thyroid tumor $(n=11,015)$ and those referred for other reasons $(n=24,010)$, the increased risk is only seen in those who were suspected of harboring a thyroid tumor ${ }^{7}$ (Table 3).

Concerning the therapeutic application of radioiodine, data derived from a longitudinal follow-up study of 10,522 patients from Sweden who had been treated with radioiodine between 1950 and 1975 are available..$^{8}$ In this group, the incidence of thyroid cancer after radioiodine therapy for benign thyroid disorders was not increased.

\section{LATE CONSEQUENCES OF THE CHERNOBYL ACCIDENT}

After the Chernobyl reactor accident on April 26,1986 , a significant increase of thyroid cancer in children and adolescents from the affected countries (Belarus, Ukraine and Western parts of Russia) has been reported. ${ }^{9}$ The highest increase in childhood cancer incidence has been reported in subjects from Belarus (Figure 1). ${ }^{10,11}$

According to a report of the UN Chernobyl Forum Expert Group Health, ${ }^{11}$ the scenario can be summarized as follows:

- Proven radiation related increase of thyroid cancer incidence in children and adolescents (total number of cases approximately 5,000; the highest incidence occurred in the age-group 0-4).

- No difference in risk between males and females. 
Table 3. Thyroid cancer after internal radiation exposure: The Swedish ${ }^{131}$ I diagnostic (1952-1969) follow-up study (1998) in 36,792 subjects $^{7}$

\begin{tabular}{|c|c|c|c|c|c|c|}
\hline \multirow[t]{2}{*}{ Age (years) } & \multicolumn{2}{|c|}{ Males } & \multicolumn{2}{|c|}{ Females } & \multicolumn{2}{|c|}{ Total } \\
\hline & Observed & SIR & Observed & SIR & Observed & SIR \\
\hline \multicolumn{7}{|c|}{ Total $(\mathrm{n}=35.025)$} \\
\hline$<=20$ & 0 & 0.00 & 3 & 1.09 & 3 & 1.01 \\
\hline $21-50$ & 7 & $* 2.27$ & 53 & $* 1.51$ & 60 & *1.57 \\
\hline$>50$ & 10 & *5.35 & 32 & *1.96 & 42 & *2.31 \\
\hline \multicolumn{7}{|c|}{ Referred for Suspicion of a Thyroid Tumour $(\mathrm{n}=11.015)$} \\
\hline$<=20$ & 0 & 0.00 & 1 & *1.18 & 1 & $* 1.14$ \\
\hline $21-50$ & 7 & $* 9.95$ & 30 & $* 2.55$ & 37 & * 2.96 \\
\hline$>50$ & 9 & $* 17.07$ & 22 & $* 3.71$ & 31 & $* 4.80$ \\
\hline \multicolumn{7}{|c|}{ Referred for other reasons $(\mathrm{n}=24.010)$} \\
\hline$<=20$ & 0 & 0.00 & 2 & 1.05 & 2 & 0.96 \\
\hline $21-50$ & 0 & 0.00 & 23 & 0.98 & 23 & 0.89 \\
\hline$>50$ & 1 & 0.75 & 10 & 0.97 & 11 & 0.94 \\
\hline
\end{tabular}

SIR: Standardized Incidence Ratio, ${ }^{*}$ Significant

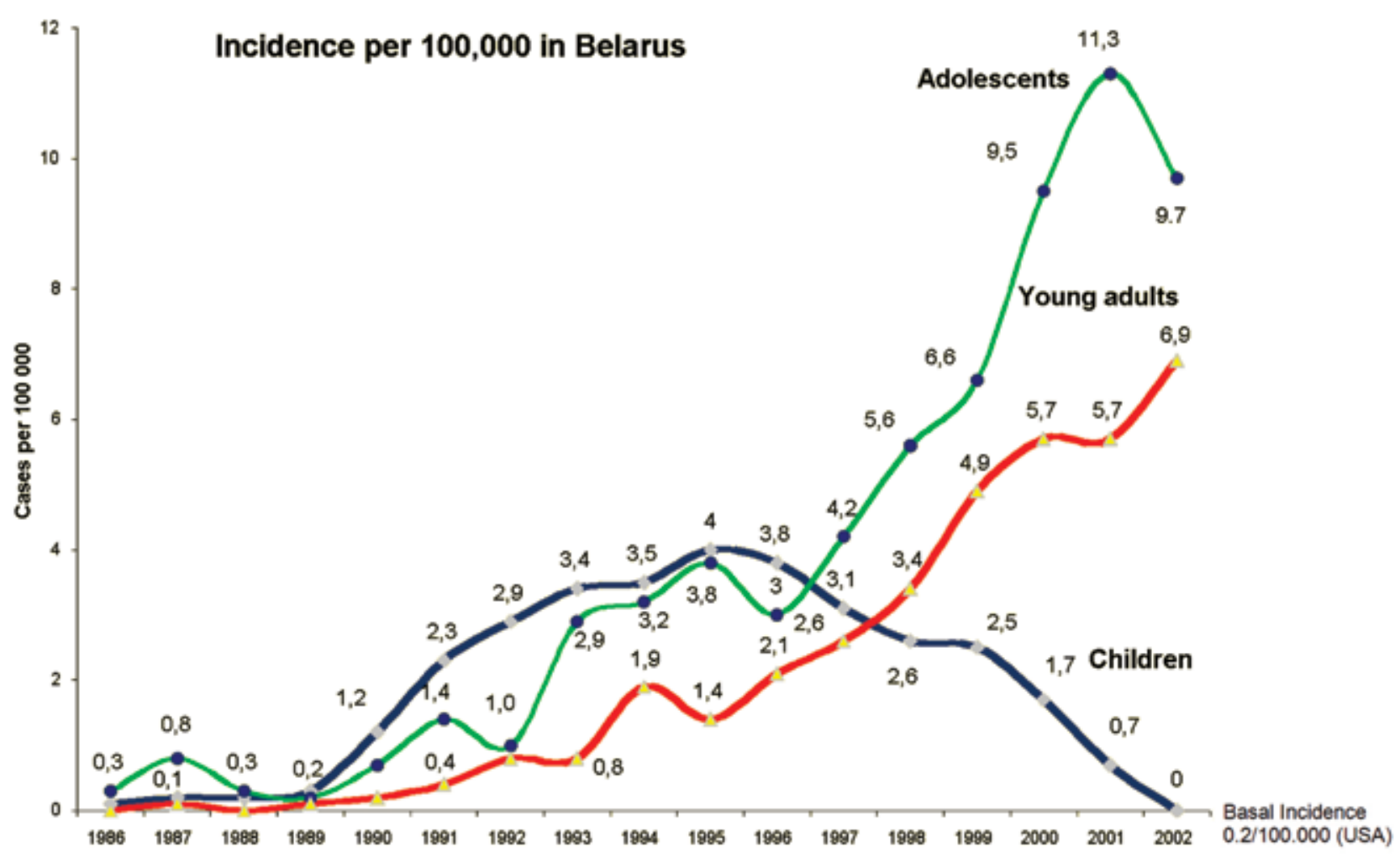

Figure 1. Thyroid cancer Incidence in children and adolescents from Belarus after the Chernobyl accident. ${ }^{10,11}$

- Thyroid cancer increase in adults unclear (not dose-related).

- Data are compatible with experience of the past after external exposure.

- Projected number of cases for 50 years (Belarus): 15,000 (uncertainty range 5,000-45,000), i.e. an 
$80 \%$ increase over baseline.

- Confounders are genetic factors, nutritional iodine status and screening modalities.

Starting April 1, 1993, a joint Belarussian-German project on the combined treatment (surgery and radioiodine) of children and adolescents from Belarus with thyroid cancer after Chernobyl was launched. Thyroid surgery was performed in the Center for Thyroid Tumors in Minsk, Belarus (Demidchik et al) ${ }^{12}$ and radioiodine therapy followed in Germany at the University of Essen (until the end of 1994) and afterwards at the University of Würzburg (Reiners et al). ${ }^{13}$

Between 1993 and 2006, 247 children from Belarus with the most advanced stages of thyroid cancer were selected for treatment in Germany. Selection criteria were advanced disease (local invasiveness, lymph node and/or distant metastases). In total, 1,047 courses of radioiodine therapy were applied during the treatment period of 13 years. The mean-age of the children at the time of the reactor accident was $2.6 \pm 2.2$ years ( $78 \%$ of the children were below the age of 5). Their age at the time of surgery ranged from 7 to 19 years with a mean-age of $12.7 \pm 2.5$ years. This corresponds to a mean latency time of approximately ten years; the shortest time-interval between exposure and surgery was 3.2 years. Sixty percent of the children were female, $40 \%$ male. Ninety-nine percent of the cancers were typed histologically as papillary and one percent as follicular carcinomas.

Sixty-three percent of the cases were selected for treatment in Germany because of tumor aggressiveness classified as stage pT4. In $97 \%$ of the cases, lymph node metastases were detected and in $43 \%$ distant metastases. With the exception of two cases with secondary tumor of the brain and bone, all distant metastases were localized in the lung. Nearly all of the patients with lung metastases presented with disseminated miliary spread and only $4 \%$ with localized nodular pulmonary lesions.

For treatment, $50 \mathrm{MBq}$ of ${ }^{131} \mathrm{I} / \mathrm{kg}$ body weight was applied to eliminate thyroid remnants. For ablation of metastases, $100 \mathrm{MBq}$ of ${ }^{131} \mathrm{I} / \mathrm{kg}$ body weight were administered. Simultaneously, antiemetics and emulsions for the protection of gastric mucosa were given to reduce gastrointestinal side-effects. Two days after treatment, replacement therapy with levothyroxine, which had been withdrawn four weeks before ${ }^{131} \mathbf{I}$ administration, was restarted. The TSH-suppressive dose amounted to $2.5 \mu \mathrm{g}$ of Levothyroxine per $\mathrm{kg}$ body weight per day. For staging, whole-body scans were performed four days after the application of radioiodine. The mean interval between two consecutive treatment courses was 4.6 months.

In 138 out of 237 children (58\%), complete remission of the thyroid cancer was achieved (negative whole-body scans and zero thyroglobulin). In 34\%, stable partial remissions could be observed (negative whole-body scans and thyroglobulin $<10 \mathrm{ng} / \mathrm{ml}$ ). In the remaining $8 \%$, stable partial remissions defined as decrease of tumor volume, thyroglobulin serum level and/or intensity of radioiodine uptake for at least $50 \%$ was observed. Reduction of tumor volume, judged quantitatively by CT measurements, as well as reduction of thyroglobulin, measured by immunoradiometric assay, were observed, the uptake reduction judged visually from posttherapy whole-body scans.

Fortunately, no single case showed progressive disease during the observation period of 13 years. It is important to mention that the results given here are not the final results of treatment since, in some cases without complete remission, further courses of radioiodine are necessary.

There is no doubt that exposure to radiation may induce thyroid cancer in children. ${ }^{3,14-16}$ According to a review by Ron et al, "The thyroid gland in children has one of the highest risk coefficients among the various organs and is the only one with convincing evidence for risk at about $0.1 \mathrm{~Gy}{ }^{3}{ }^{3}$ Linearity best describes the dose response in children exposed to radiation before the age of 15 years. Risk decreases significantly with increasing age at exposure, with little risk apparent after age 20 . The excess relative risk seems to be higher for females than for males. ${ }^{3}$

Latency times between radiation exposure and development of thyroid cancer range from a minimum of 3-7 years to a maximum of 40-50 years. Between 10 and 15 years, a nadir of the statistical distribution may be presumed. ${ }^{16}$ The relative incidence of thyroid cancer per 100,000 children below the age of 15 years increased in Belarus from 0.1 to 0.3 cases 
in the period 1986 to 1989 and to 4.0 cases in 1995. For comparison, according to figures from the USA (www.seer.cancer.gov) and data from the local cancer registry of Würzburg, Germany, the incidence of thyroid cancer below the age of 15 years ranges from 0.3 to 0.5 cases per 100,000 .

It has been claimed that malignant thyroid tumors after external irradiation typically present as papillary cancers in more than $85 \%$ of the exposed children and adolescents ${ }^{3,16}$ However, Samaan et $a{ }^{17}$ showed that when comparing two cohorts of thyroid cancer patients with and without a history of head and neck irradiation in childhood, the proportion of papillary cancers in those two cohorts was not different $(87 \%$ and $84 \%$, respectively). Comparison with other data from the literature (Luster et al) ${ }^{18}$ proves that papil- lary histology per se is typical for thyroid cancer in childhood and adolescents (Table 4).

According to Samaan's study, bilateral lobe involvement $(51 \%)$ and cancer not limited to the thyroid gland $(70 \%)$ seemed to be characteristic for radiationinduced thyroid cancer. ${ }^{17}$ This observation, however, could not be replicated by the observations which have been made in children with radiation induced thyroid cancer after Chernobyl.

Generally, prognosis of thyroid cancer in children and adolescents is reported to be excellent (Table 5). ${ }^{12,18-25}$ The mortality is usually low, ranging from 1 to $2 \%$. However, recurrence rates are usually in the range of $30 \%$. This clearly indicates that lifelong follow-up of childhood thyroid cancer is necessary.

Table 4. Number of patients, mean follow-up, histological type and tumor stage of Thyroid cancer in Children and Adolescents (studies with more than 50 patients are included)

\begin{tabular}{|c|c|c|c|c|c|c|c|}
\hline Author (references) & Year & Patients (n) & Follow up (months) & Histology PTC (\%) & pT4 (\%) & pN1 (\%) & pM2 $(\%)$ \\
\hline Schlumberger $^{19}$ & 1987 & 72 & n.a. & n.a. & 67 & 90 & 18 \\
\hline Zimmermann $^{20}$ & 1988 & 68 & 331 & 100 & 24 & 90 & 7 \\
\hline LaQuaglia $^{21}$ & 1988 & 103 & 240 & 84 & 24 & 71 & 19 \\
\hline Dottorini $^{22}$ & 1997 & 85 & 111 & 85 & 31 & 60 & 19 \\
\hline Vassilopoulou-Selin ${ }^{23}$ & 1998 & 112 & 112 & 92 & 38 & 63 & 28 \\
\hline Segald $^{24}$ & 1998 & 61 & n.a. & 79 & 26 & 49 & 6 \\
\hline Newman $^{25}$ & 1998 & 329 & 136 & 90 & 32 & 74 & 25 \\
\hline LaQuaglia ${ }^{26}$ & 2000 & 83 & 131 & 90 & 48 & 90 & 100 \\
\hline Jarzab $^{27}$ & 2000 & 109 & 60 & 71 & n.a. & 59 & 16 \\
\hline Grigsby $^{28}$ & 2001 & 56 & 132 & 95 & 54 & 60 & 13 \\
\hline Chow $^{29}$ & 2004 & 60 & 168 & 82 & 23 & 45 & 15 \\
\hline Popovtzer $^{30}$ & 2006 & 75 & n.a. & 83 & n.a. & 60 & 6 \\
\hline Handkiewicz $^{31}$ & 2007 & 235 & 82 & 82 & 8 & 40 & 17 \\
\hline Rybakov $^{32}$ & 2000 & 330 & 180 & 94 & 55 & 62 & 15 \\
\hline Demidchik $^{12}$ & 2006 & 741 & 97 & 95 & 16 & 69 & 18 \\
\hline
\end{tabular}

LN: Lymph Node, n.a.: Not Available, PTC: Papillary thyroid cancer 
Table 5. Treatment, side-effects and outcome of Thyroid cancer in Children and Adolescents (studies with more than 50 patients are included)

\begin{tabular}{|c|c|c|c|c|c|c|c|c|c|}
\hline Author (references) & 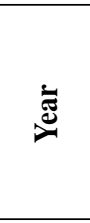 & 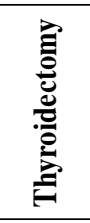 & 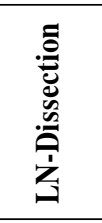 & 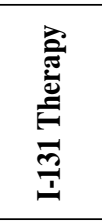 & $\underset{\Xi}{ \pm}$ & 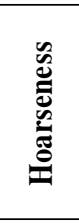 & 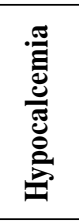 & 营 & 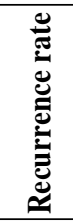 \\
\hline Schlumberger ${ }^{19}$ & 1987 & $40 \%$ & n.a. & $22 \%$ & n.a. & $11 \%$ & $7 \%$ & n.a. & $58 \%$ \\
\hline Zimmermann $^{20}$ & 1988 & $76 \%$ & $60 \%$ & $20 \%$ & Most. & $0 \%$ & $24 \%$ & $15 \%$ & $48 \%$ \\
\hline LaQuaglia $^{21}$ & 1988 & $45 \%$ & $73 \%$ & $21 \%$ & $80 \%$ & $30 \%$ & $32 \%$ & $0 \%$ & $34 \%$ \\
\hline Dottorini $^{22}$ & 1997 & $56 \%$ & n.a. & $89 \%$ & Most. & $4 \%$ & $8 \%$ & $0 \%$ & $7 \%$ \\
\hline Vassilopoulou-Selin ${ }^{23}$ & 1998 & $72 \%$ & $62 \%$ & Most. & Most. & n.a. & n.a. & $29 \%$ & $40 \%$ \\
\hline Segald $^{24}$ & 1998 & $83 \%$ & $59 \%$ & $100 \%$ & $100 \%$ & $10 \%$ & $10 \%$ & $3 \%$ & $33 \%$ \\
\hline Newman ${ }^{25}$ & 1998 & $54 \%$ & $56 \%$ & $43 \%$ & n.a. & $2 \%$ & $12 \%$ & $1 \%$ & $33 \%$ \\
\hline LaQuaglia ${ }^{26}$ & 2000 & $66 \%$ & $51 \%$ & $100 \%$ & $100 \%$ & $1 \%$ & $12 \%$ & $0 \%$ & $31 \%$ \\
\hline Jarzab $^{27}$ & 2000 & $100 \%$ & $100 \%$ & $100 \%$ & $100 \%$ & $10 \%$ & $6 \%$ & $0 \%$ & $15 \%$ \\
\hline Grigsby $^{28}$ & 2001 & $92 \%$ & $95 \%$ & $82 \%$ & $100 \%$ & $0 \%$ & $7 \%$ & $0 \%$ & $34 \%$ \\
\hline Chow $^{29}$ & 2004 & $82 \%$ & $87 \%$ & $60 \%$ & $100 \%$ & n.a. & n.a. & $3 \%$ & $22 \%$ \\
\hline Popovtzer ${ }^{30}$ & 2006 & $89 \%$ & $100 \%$ & $89 \%$ & $100 \%$ & $12 \%$ & $5 \%$ & $3 \%$ & $9 \%$ \\
\hline Handkiewicz ${ }^{31}$ & 2007 & $73 \%$ & $67 \%$ & $74 \%$ & $100 \%$ & n.a. & n.a. & $0 \%$ & $14 \%$ \\
\hline Rybakov $^{32}$ & 2000 & $84 \%$ & $57 \%$ & $75 \%$ & $100 \%$ & $12 \%$ & $6 \%$ & $2 \%$ & $7 \%$ \\
\hline Demidchik $^{12}$ & 2006 & $58 \%$ & $82 \%$ & $63 \%$ & $100 \%$ & $6 \%$ & $12 \%$ & $1 \%$ & $28 \%$ \\
\hline
\end{tabular}

after Chernobyl, LN: Lymph Node, n.a: Not Available

\section{REFERENCES}

1. Brent GA, Braverman LE, Zoeller RT, 2007 Thyroid health and the environment. Thyroid 17: 807-809.

2. Schneider AB, Sarne DH, 2005 Long-term risks for thyroid cancer and other neoplasms after exposure to radiation. Nat Clin Pract Endocrinol Metab 1: 82-91.

3. Ron E, Preston DL, Mabuchi K, 1995 More about cancer incidence in atomic bomb survivors: solid tumors, 19581987. Radiat Res 141: 126-127.

4. Nagataki S, Shibata Y, Inoue S, Yokoyama N, Izumi M, Shimaoka K, 1994 Thyroid diseases among atomic bomb survivors in Nagasaki. JAMA 272: 364-370.

5. Imaizumi M, Usa T, Tominaga T, et al, 2006 Radiation dose-response relationships for thyroid nodules and autoimmune thyroid diseases in Hiroshima and Nagasaki atomic bomb survivors 55-58 years after radiation exposure. JAMA 295: 1011-1022.

6. Thompson DE, Mabuchi K, Ron E, et al, 1994 Cancer incidence in atomic bomb survivors. Part II: Solid tumors,1958-1987. Radiat Res 137: Suppl 2: 17-67.

7. Dickman PW, Holm LE, Lundell G, Boice JD Jr, Hall P, 2003 Thyroid cancer risk after thyroid examination with ${ }^{131} \mathrm{I}$ : a population-based cohort study in Sweden. In J Cancer 106: 580-587.

8. Hall P, Holm LE, 1997 Late consequences of radioiodine for diagnosis and therapy in Sweden. Thyroid 7: 205-208.
9. Ron E, 2007 Thyroid cancer incidence among people living in areas contaminated by radiation from the Chernobyl accident. Health Phys 93: 502-511.

10. Demidchik YE, Demidchik EP, Saenko VA, et al, 2007 Childhood thyroid cancer in Belarus. International Congress Series 1299: 32-38.

11. Cardis E, Howe G, Ron E, et al, 2006 Cancer consequences of the Chernobyl accident: 20 years on. J Radiol Prot 26: 127-140.

12. Demidchik YE, Demidchik EP, Reiners C, et al, 2006 Comprehensive clinical assessment of 740 cases of surgically treated thyroid cancer in children of Belarus. Ann Surg 243: 525-532.

13. Reiners C, Biko J, Demidchik YE, Drozd VM, 2007 Benefit and side-effects of radioiodine therapy in radiation-induced childhood carcinoma. International Congress Series 1299: 174-182.

14. Akiba S, Lubin J, Ezaki E, et al, 1991 Thyroid cancer incidence among atomic bomb survivors in Hiroshima and Nagasaki 1958-1979, Technical report TR 5-91. Radiation Effects Foundation, Hiroshima, Japan.

15. Hall P, Holm LE, 1998 Radiation-associated thyroid cancer - facts and fiction. Acta Oncol 37: 325-330.

16. Shore RE, 1992 Issues and epidemiological evidence regarding radiation-induced thyroid cancer. Radiat Res 131: 98-111.

17. Samaan NA, Schultz PN, Ordonez HG, Hickey RC, Johnston DA, 1987 A comparison of thyroid carcinoma 
in those who have and have not had head and neck irradiation in childhood. J Clin Endocrinol Metab 64: 219-223.

18. Luster M, Lassmann M, Freudenberg LS, Reiners C, 2007 Thyroid cancer in childhood: management strategy, including dosimetry and long-term results. Hormones (Athens) 6: 269-278.

19. Schlumberger M, De Vathaire F, Travagli JP, et al, 1987 Differentiated thyroid carcinoma in childhood: long term follow-up of 72 patients. J Clin Endocrinol Metab 65: 1088-1094.

20. Zimmerman D, Hay ID, Gough IR, et al, 1988 Pappilary thyroid carcinoma in children and adults: long-term follow-up of 1039 patients conservatively treated at one institution during three decades. Syrgery 104: 11571166.

21. La Quaglia MP, Corbally MT, Heller G, Exelby PR, Brennan MF, 1988 Recurrence and morbidity in differentiated thyroid carcinoma in children. Surgery 104: 1149-1156.

22. Dottorini ME, Bignati A, Mazzucchelli L, Lomuscio G, Colombo L, 1997 Differentiated thyroid carcinoma in children and adolescents: a 37-year experience in 85 patients. J Nucl Med 38: 669-675.

23. Vassilopoulou-Sellin R, Goepfert H, Raney B, Schultz PN, 1998 Differentiated thyroid cancer in children and adolescents: clinical outcome and mortality after longterm follow-up. Head Neck 20: 549-555.

24. Segal K, Shvero J, Stern Y, Mechlis S, Feinmesser R, 1998
Syrgery of thyroid cancer in children and adolescents. Head Neck 20: 293-297

25. Newman KD, Black T, Heller G, et al, 1998 Differentiated thyroid cancer: determinants of disease progression in patients $<21$ years of age at diagnosis: a report from the Surgical Discipline Committee of the Children's Cancer Group. Ann Surg 227: 533-541.

26. La Quaglia MP, Black T, Holcomb GW $3^{\text {rd }}$, et al, 2000 Differentiated thyroid cancer: clinical characteristics, treatment and outcome in patients under 21 years of age who present with distant metastases. A report from the Surgical Discipline Committee of the Children's Cancer Group. J Pediatr Surg 35: 955-959.

27. Jarzab B, Handkiewicz Junak D, Wloch J, et al, 2000 Multivariate analysis of prognostic factors for differentiated thyroid carcinoma in children. Eur J Nucl Med 27: 883-841.

28. Grigsby PW, Gal-or A, Michalski JM, Doherty GM, 2002 Childhood and adolescent thyroid carcinoma. Cancer 95: 724-729.

29. Chow SM, Law SC, Mendenhall WM, et al, 2004 Differentiated thyroid carcinoma in childhood and adolescence-clinical course and role of radioiodine. Pediatr Blood Cancer 42: 176-183.

30. Popovtzer A, Shpitzer T, Bahar G, Feinmesser R, Segal K, 2006 Thyroid cancer in children: management and outcome experience of a referral centre. Otolaryngol Head Neck Surg 135: 581-584. 